\title{
BIM DESIGN FLOW FOR CONSTRUCTION SITE
}

\author{
MARCO L. TRANI, MANUELE CASSANO, and DAVIDE TODARO
}

A.B.C. Dept, Politecnico di Milano, Milano, Italy

\begin{abstract}
Construction site planning is an important task in a design team whereas a proper design of construction activities has a great influence in time and cost saving as well as in workers' safety. Designers need to focus on site planning since the preliminary phase of building design in order to point out construction criticalities of the project that can affect execution phase. On the contrary, a scarce attention to operational issues during design phase is detectable in industry. Despite of the rapid diffusion of Building Information Modeling (BIM), a lack of BIM tools specifically studied for site design is detectable. Then the purpose of this paper is to describe a workflow developed with the aim to integrate site planning in a BIM design process, gaining thus operational advantages. The development of the workflow follows designers' needs collected through the active participation of the authors in several design teams. A strong coordination and information sharing with other disciplines is the main task of the workflow, so that design choices can take into consideration operational issues as well. In order to simplify and accelerate the tasks of the site designer, the system is based on the use of some tools (such as databases of construction site elements and automatic checking tools), specifically developed for the purpose. The satisfaction of the designers involved demonstrates the efficiency of the system, in particular concerning the decrease of design time and the assistance of design choices thanks to operational information management.
\end{abstract}

Keywords: Building information modeling, Construction safety, Design optimization, Operational information, Construction simulation.

\section{INTRODUCTION}

The planning of construction site activities since the early design phases has a great impact on the success of the subsequent execution phase (Hare et al. 2006). In particular a preliminary construction site design has the main task to point out construction criticalities of the project that can affect execution phase in term of time, cost and safety loss. If studied during the whole design phase, these criticalities may be solved before affecting construction performances or, if not possible, faced with the right awareness during works. In order to reach this goal a construction site designer has to join the design team from the early stages of the project. In fact all designers have to strongly collaborate, not only to avoid design errors but also to guarantee the real feasibility of the designed works. Only a deep information exchange (between the designers of the building elements and the designer of the works to put in place these elements) can guarantee the fulfillment of such an objective. Regarding in particular safety issues, this collaboration is underlined also by legislation about safety (e.g., European directive 92/57/EEC and related national versions). On the contrary, a scarce 
attention to operational issues during design phase is diffused in the construction industry. Nowadays Building Information Modeling (BIM) is certainly the most popular method to assure collaborative design. Its quick diffusion and its well-known advantages make it a powerful tool also for construction site design, since the possibility to collect and share information in a unique platform. Nevertheless, a lack of BIM tools specifically studied for construction site design is detectable among BIM software. For this reason, the ongoing research aims to develop a precise workflow to integrate site design in a BIM design process. The site design becomes thus a part of design workflow since the preliminary phase by the development of a proper Construction site information Model (CoSIM).

\section{BIM AND CONSTRUCTION SITE LAYOUT PLANNING}

Since many years BIM has been studied as a collaborative tool able to optimize the building design process. Lot of research developed BIM tools in different disciplines and some studies concern particularly the site layout planning. Vimonsatit et al. (2014) underline the possibility to enhance site planning thanks to simulations and BIM that shows available spaces throughout the construction stage. Lot of the researches that concerns construction sites are indeed focused on construction scheduling (with the implementation of 4D models) and safety planning. In particular from many years researches on 4D scheduling have been carried out starting from 4D CAD tools (Zhou et al. 2012) to 4D BIM and use of data to generate schedules (Kim et al. 2013). In general the main goal is to facilitate safety planning production (Azhar et al. 2012) ensuring a detail level suitable for hazard identification before starting construction. The VTT Technical Research Centre of Finland studied deeply BIM tools for construction site layout and safety planning focusing on the visualization potentiality of BIM for the managing and communicating safety plans by BIM (Kiviniemi et al. 2011). Such a research focused also the need of a creation of objects libraries of temporary structures and equipment (Sulankivi et al. 2009). The researches on the field focused on single aspects of construction planning (safety, scheduling, costs, etc.). The presented research aims to go ahead single applications and give an overview of the design process by showing design steps that a site designer need to follow according to the development of the project.

\section{CONSTRUCTION SITE INFORMATION MODELING}

The development of the method focused on two main research environments. The first one concerns the deep study of the actual standards for building design. Furthermore, in order to guarantee the usefulness of the method, the authors collaborated in several design team and got the needs specifically expressed by the designers involved. Moreover, the created workflow follows precise design steps in order to guarantee the integration with other disciplines during the whole design development. In particular the method takes into consideration three main phases of the design to be carried on before the tender phase (Draft, Developed and Detailed design). Such a simple and schematized model is taken into account for the development of the CoSIM workflow in order to comply as much as possible both the design tendencies of those countries that still not have BIM regulations and some of available BIM standards (e.g., UK PAS 
1192-2:2013). Each phase has the aim of complying, as much as possible, the needs of all designers in order to gain an integrated model. A particular attention is given to the information contained in the construction model and the relationships between these information and the design information contained in the building model. The result of the whole workflow is a model ready for the tender and, then, for the chosen contractor that can properly implement it in the execution design.

\subsection{Concept Pre-Design}

The concept design starts with the preliminary draft of the intervention and shows, in particular, the first ideas of the construction by the implementation of surfaces, volumes and shapes. In this first design step the site designers has in particular the main tasks of the modeling of the Construction site master plan around the volumes. Then is possible to define the first shape of the construction site and to introduce a first brief of the logistic plan in order to verify the available spaces and the surrounding situation. So the concept "Site \& Surrounding model" has the principal aims of underline the needs in term of construction spaces and evaluate the possible impact of the adjacent constraints. The constraints founded need to be underlined and to be subject to a proper risk assessment in order to evaluate the possible solution to be carried on (e.g., elimination of the constraints, protection, bypassing etc.). Concept phase, as the following phases, has to be concluded by a final checking between the different models created by different actors in order to avoid possible interferences.

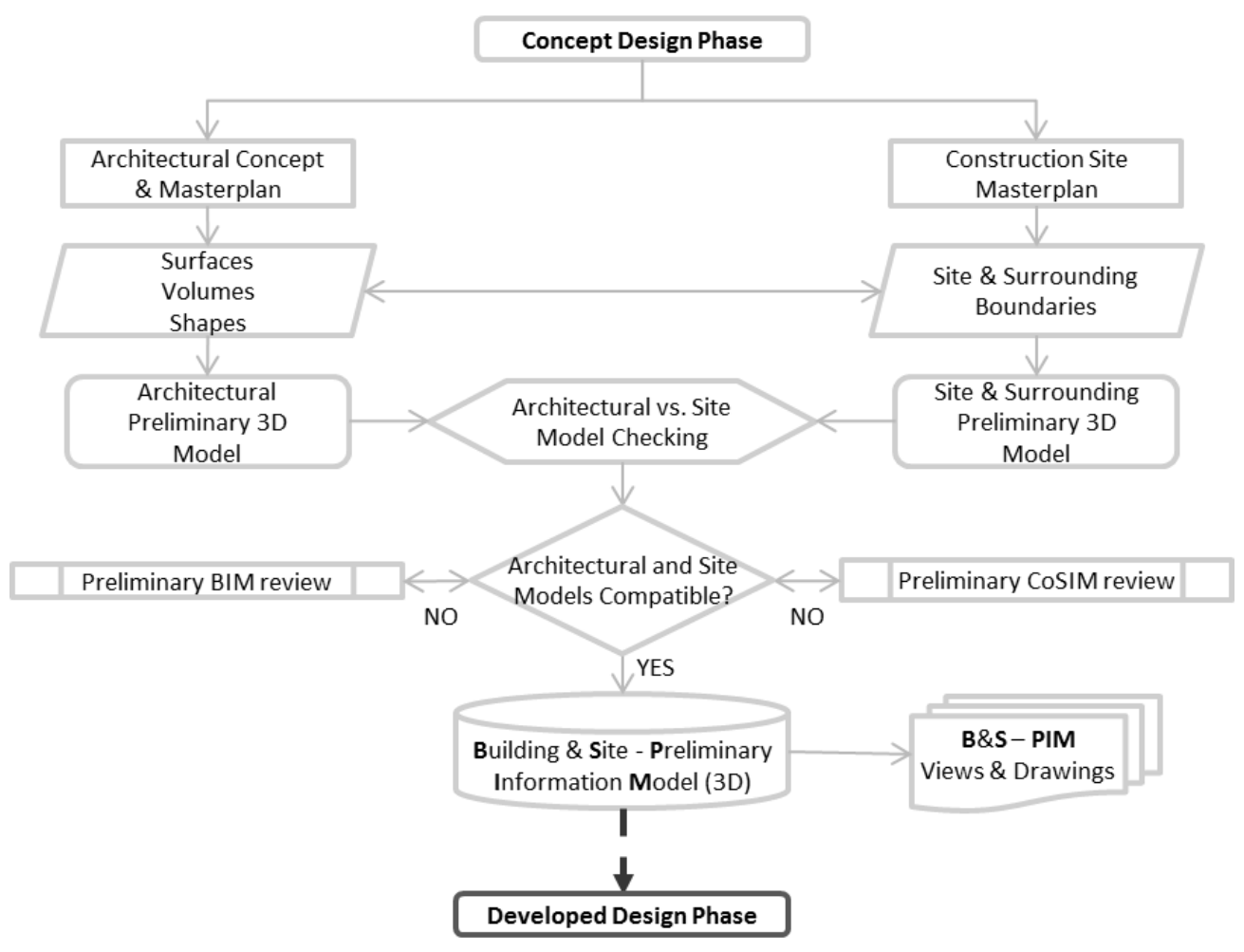

Figure 1. Concept pre-design workflow. 


\subsection{Developed Pre-Design}

In the developed design phase the main task is the design of the construction site logistic plan. In this phase the designers insert information about the singular building systems and their technical solutions. This way the intervention becomes clear and the site designer can focus on these elements by developing a proper construction breakdown structure. Through this he recognize the works to be carried out and it is now able to check the building operational information (e.g., the weight of a structural element) with the site information (the load of the crane) in order to choose the right element to put in place. Hence, the building system technical solutions are placed, side by side, near the Site System technical solutions in order to build the Developed Construction site Information Model. Substantially it represents the construction site layout in the different main phases of the construction process. The developed model is thus characterized by the insertion of an adequate number of site elements completed with their information useful to be matched with building operation information for the choice of the site element itself as well as its position in the site logistic. This issue underlines, in particular in this phase and in the next, the need of a proper library of site elements, not yet so diffused and complete in term of graphical and information details. As in the concept phase, also in developed phase the CoSIM needs to be checked with the others in order to not compromise the rightness of the project. The Building \& Site - System Information Model is the result of the developed design and represents a dimensionally correct and coordinated model (PAS 1192-2:2013) able to be submitted for authority permissions.

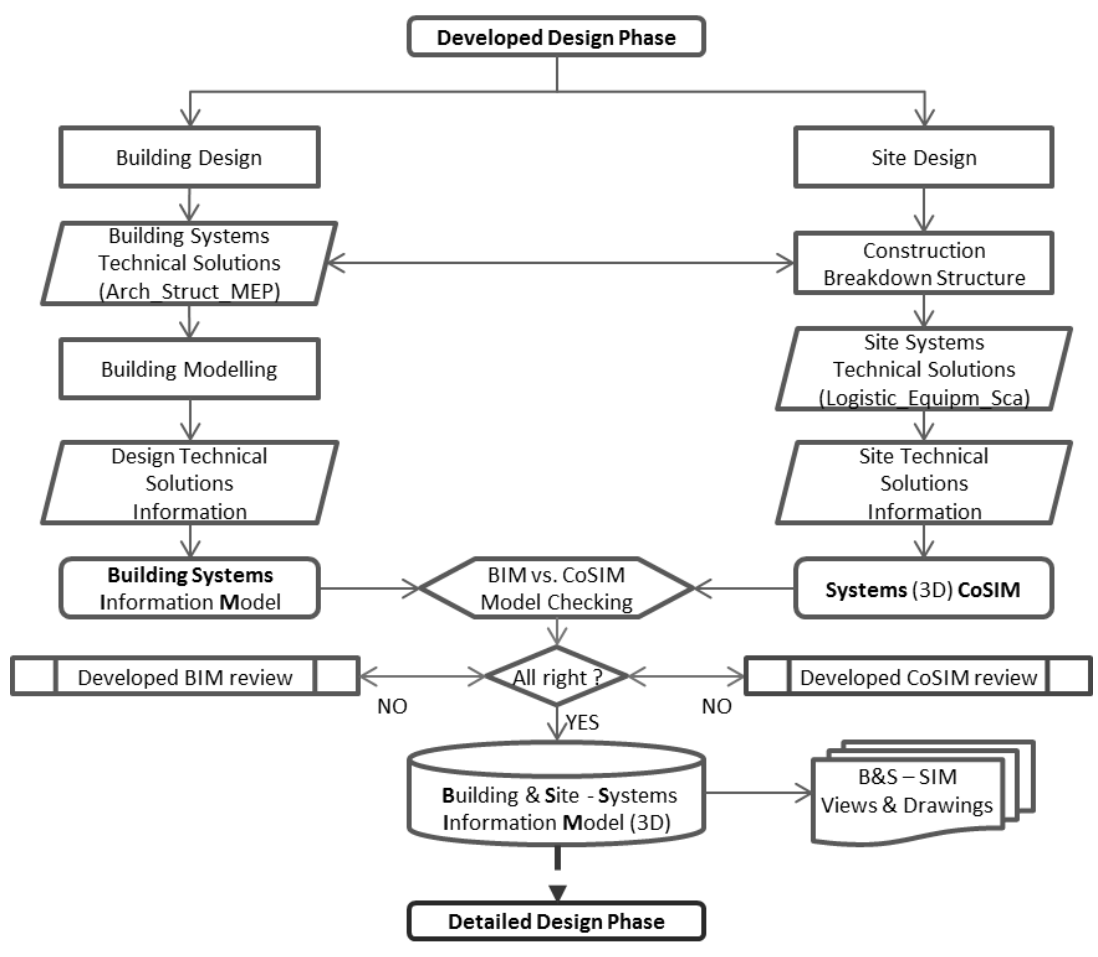

Figure 2. Developed pre-design workflow. 


\subsection{Detailed Pre-Design}

The detailed design phase has the aim to create the final model to be used for the tender. The main task for the site designer in this phase is to have a deep information exchange (through the model) with the other designers about the detailed technological choices. Thanks to these information about the building, the site designer has to manage the operational information in order to evaluate each single work to be carried out and produce a 4D work plan. To do this he has to add to the model further data concerning resources such as work force and unit times. All these information about the single works permit to design each work-zone by defining minimum spaces, temporary structures and possible equipment needed. Therefore the 4D Work plan permits to verify the need of some contemporary works and to assess the risk of interference between these works. The risk assessment permits to solve previously the interferences between works by changing the site design solution (e.g., adding different safety devices) or modifying the work plan with a time shift of the interferential works. Through this, the site designer is able to previously verify the feasibility of the works in a precise context (environment, expected time and costs, safety, etc.) and to give back to the design team information for changing the design solutions if it can create problems to the success of the project. After the tender the model is transmitted to the contractor that becomes the principal actor of design and has to produce the construction model. It represent the final model able to manage construction and has to contain all the elements (both of the building and of the construction site) that will really be used for construction.

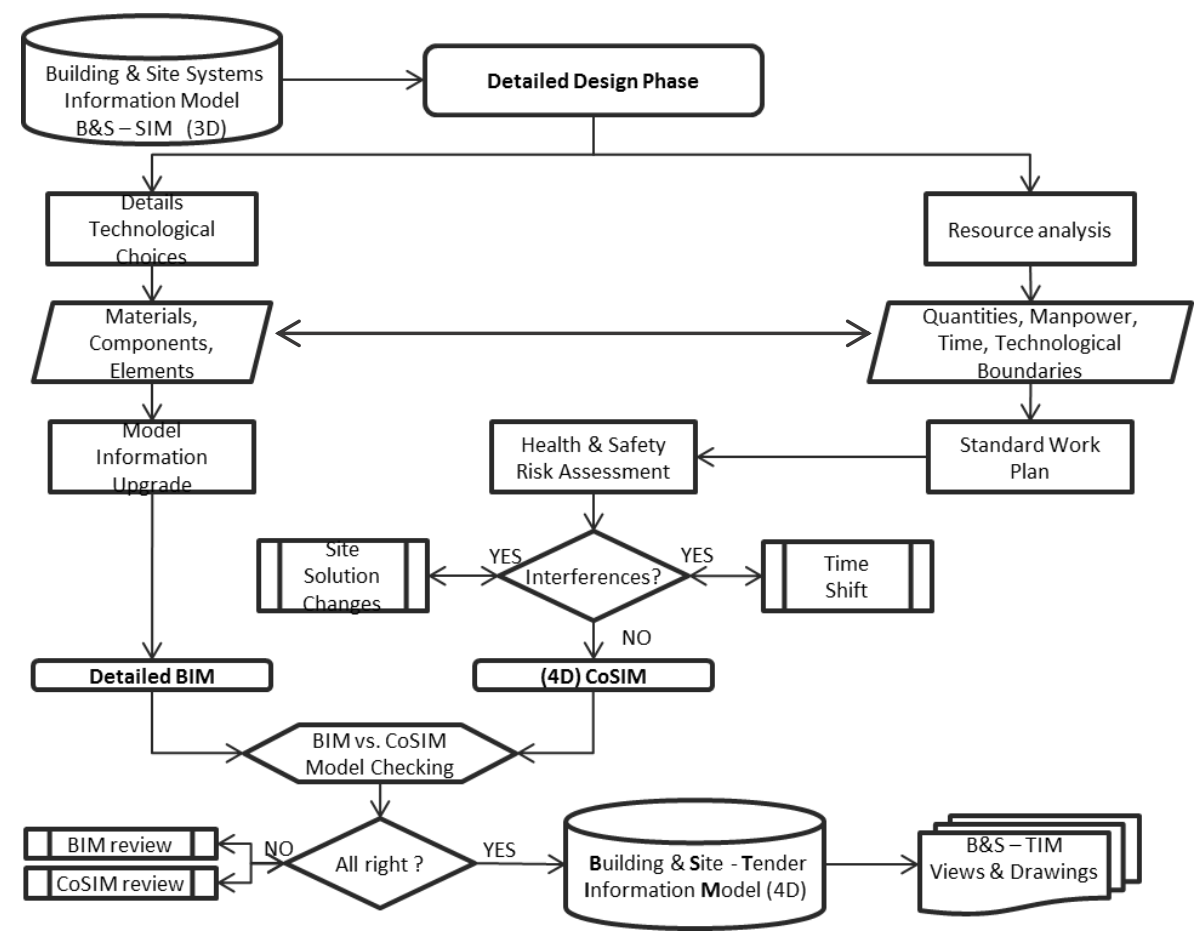

Figure 3. Detailed pre-design workflow. 


\section{DISCUSSION AND CONCLUSIONS}

The development of the method follows the needs of some designers involved in real design contexts. Thanks to these experiences we made many tests about the efficiency of BIM tools for construction site design in this environment, finding both strength points and weaknesses. Obviously the availability of information in a model means efficient information exchange decreasing design time. However, especially regarding site design, BIM tools are not yet properly developed. In fact, in order to efficiently manage the site design, we created a library of BIM elements typical of construction site (equipment, temporary structures etc.) containing the needed info for design choices (Trani et al. 2014). Furthermore we store all the studied elements in a database equipped of information searching and checking tools in order to make more efficient and fast information exchange (Trani et al. 2015). However there are many elements to be developed in order to make the method more efficient. In fact the development of the library and the database is still in progress. Both the research among the datasheets and the modeling of the elements require an amount of time not compatible with design time. For this reason, finished libraries and databases are required in order to manage faster the whole process. Anyway the results encourage the task group to continue the improvements of the CoSIM method in order better manage construction projects thanks to an increased consciousness of operational issues in the design phase. The path traced is still long and must take into consideration the principal need to introduce BIM among construction professionals and companies. The CoSIM should be an efficient method in a BIM context with the aim of better managing and automating some choice, with the think that must be used not as the solution of any problem but as a design support for decision making that remains, anyway, a designer's task.

\section{References}

Azhar, S., Behringer, A., Sattineni, A., Maqsood, T., 2012. BIM for Facilitating Construction Safety Planning and Management at Jobsites, in: CIB W099 International Conference on Modelling and Building Health and Safety. pp. 82-92.

Hare, B., Cameron, I., Roy Duff, a., 2006. Exploring the integration of health and safety with pre-construction planning. Eng. Constr. Archit. Manag. 13.

Kim, H., Anderson, K., Lee, S., Hildreth, J., 2013. Generating construction schedules through automatic data extraction using open BIM technology. Autom. In Constr. 35, 285-295.

Kiviniemi, M., Kähkönen, K., Mäkelä, T., Merivirta, M.-L., Sulankivi, K., 2011. BIM-based Safety Management and Communication for Building Construction, Vtt Tiedotteita Research Notes 2597.

Sulankivi, K., Mäkelä, T., Kiviniemi, M., 2009. BIM-based site layout and safety planning, in: VTT Symposium (Valtion Teknillinen Tutkimuskeskus). pp. 125-140.

Trani, M.L., Cassano, M., Minotti, M., Todaro, D., 2014. Construction site BIM requirements. Proc. 30th Annu. Assoc. Res. Constr. Manag. Conf. ARCOM 2014, 663-672.

Trani, M., Bossi, B., Cassano, M., Todaro, D., 2015. BIM oriented equipment choice on construction site, in: ISEC 2015, Sust. Sol. In Struct. Eng. And Constr. pp. 1139-1144.

Vimonsatit, V., Lim, M., 2014. Use of BIM tools for site layout planning, in: ISEC 2015, Sustainable Solutions in Structural Engineering and Construction. pp. 755-760.

Zhou, W., Georgakis, P., Heesom, D., Feng, X., 2012. Model-based groupware solution for distributed real-time collaborative 4D planning via teamwork, Joutnal of Computing in Civil Engineering. 26 (5). Pp 597-611 